\title{
Distribuição da população e cobertura da terra: o lugar das Áreas Protegidas no Pará, Brasil em 2010*
}

\author{
Álvaro de Oliveira D’Antona** \\ Ricardo de Sampaio Dagnino ${ }^{\star \star \star}$ \\ Maria do Carmo Dias Bueno ${ }^{\star \star \star \star}$
}

O objetivo deste artigo é analisar a distribuição da população do Pará, a partir de dados do Censo Demográfico 2010 associados a dados de uso e cobertura da terra do TerraClass, dispostos em uma grade estatística. Verifica-se o papel de 113 Áreas Protegidas (AP) - 46 Terras Indígenas, 51 Unidades de Conservação de Uso Sustentável e 16 Unidades de Conservação de Proteção Integral - no gradiente rural-urbano do ponto de vista populacional e em relação aos usos-coberturas da terra nelas existentes. Utilizando um Sistema de Informações Geográficas, os dados relativos às APs, ao uso e cobertura da terra e os censitários foram incorporados à grade estatística. 0 relacionamento espacial dos planos de informação nas células indica que a população do estado é bastante concentrada, uma tendência que se reproduz nas Áreas Protegidas (o coeficiente de Gini para a distribuição dos domicílios é superior a 0,9). As APs configuram-se como áreas menos populosas e mais florestadas em comparação ao restante do estado. Apesar da presença de extensas porções sem domicílios ocupados e da maior extensão de florestas do Pará (57\%), identificam-se nestas áreas usos urbanos associados a outros usos e coberturas da terra. Os resultados indicam que as dinâmicas populacionais e as mudanças nos usos e cobertura da terra estão relacionadas de forma mais ampla, estimulando a reflexão sobre a urbanização e as mudanças no uso e cobertura da terra de forma mais integrada.

Palavras-chave: Pará. Áreas Protegidas. Distribuição espacial. Grade estatística. Uso e cobertura da terra.

\footnotetext{
* Os autores agradecem ao Conselho Nacional de Desenvolvimento Científico e Tecnológico pelo apoio (MCTI/CNPq/ Universal 456096/2014-0).

** Faculdade de Ciências Aplicadas, Universidade Estadual de Campinas (FCA/Unicamp), Campinas-SP, Brasil (alvaro. dantona@fca.unicamp.br).

*** Faculdade de Ciências Aplicadas, Universidade Estadual de Campinas (FCA/Unicamp), Campinas-SP, Brasil (ricardosdag@ gmail.com).

${ }_{\star \star \star \star \star}$ Instituto Brasileiro de Geografia e Estatística (IBGE), Rio de Janeiro-RJ, Brasil (bueno.mariadocarmo@gmail.com).
} 


\section{Introdução}

A emergência do campo de População e Ambiente, desde as últimas décadas do século XX, explicitou a necessidade de integrar, aos estudos, elementos sobre população, meio ambiente e desenvolvimento sustentável (MARTINE, 2007; HOGAN, 2007), bem como buscar novas teorias para lidar com a complexidade dos temas estudados e novos métodos para trabalhar com as extensões espacial e temporal envolvidas (LUTZ; PRSKAWETZ; SANDERSON, 2002). Apesar dos avanços conceituais e metodológicos desde então, detecta-se ainda a necessidade de incorporação mais sistemática do espaço nos estudos de população, tanto da perspectiva instrumental quanto da conceitual, desenvolvimento de abordagens multiescalares, incluindo modelos multiníveis (BARBIERI, 2007; GARDNER et al., 2013), diálogo interdisciplinar mais amplo (CÔRTES; D’ANTONA, 2014).

0 artigo busca contribuir para o desejável diálogo pela aproximação dos estudos das mudanças no uso e cobertura da terra com aqueles voltados para a distribuição e dispersão urbana na Amazônia. Especificamente, verifica-se o papel, ou lugar, das Áreas Protegidas (AP) do Estado do Pará - Terras Indígenas (TI) e Unidades de Conservação (UC) - no gradiente rural-urbano, levando em conta medidas de concentração da população e o uso e cobertura da terra. Ao definirem regras de ocupação e de uso de recursos, as APs afetam a distribuição da população. Cabe avançar na compreensão das relações de tais unidades no quadro regional, tendo em vista seus potenciais impactos sobre a rede urbana (SATHLER et al., 2009) e os possíveis impactos da rede urbana sobre os ecossistemas protegidos (GUEDES; COSTA; BRONDÍZIO, 2009).

Nesse sentido, o Estado do Pará chama a atenção: é a unidade da Federação da Amazônia Legal com o menor percentual de população residente em áreas urbanas 68,5\%, contra $72 \%$ nos estados da Amazônia (IBGE, 2011a) -; tem um dos maiores percentuais de território coberto por Áreas Protegidas; e suas taxas de desmatamento estão entre as mais elevadas da Amazônia.

Além disso, busca-se contribuir para o desenvolvimento dos estudos sobre população e ambiente em Áreas Protegidas, por meio do enfrentamento da limitação gerada pelo uso de dados demográficos agregados em unidades político-administrativas e operacionais. Sabe-se que a grade com células regulares melhora a resolução espacial dos dados e permite abstrair os limites de setores censitários e municípios, proporcionando uma melhor aderência às Unidades de Conservação (D'ANTONA; BUENO; DAGNINO, 2013). Aqui, o emprego prioritário de técnicas de agregação de dados do Universo do Censo Demográfico 2010 (IBGE, 2011a) possibilita que a localização dos domicílios não dependa de camadas auxiliares, como a cobertura da terra e estradas, constituindo um avanço em estudos no Brasil, somente possível a partir do último Censo Demográfico. 


\section{Dinâmicas de ocupação, uso e cobertura da terra}

Não se pode ignorar as mais contemporâneas transformações do rural, as quais não deveriam ser vistas de forma desconectada das cidades, onde a população se concentra, demanda e, geralmente, legisla para além do urbano. As fronteiras rural-urbano estão cada vez mais difusas e imbricadas (MONTE-MÓR, 2006) também pelo caráter não agrícola das áreas rurais - incluindo as atividades como o turismo e a conservação da natureza (SILVA, 1997, p. 47).

As dinâmicas populacionais e as mudanças nos usos e coberturas da terra devem ser relacionadas de uma perspectiva analítica mais ampla e integrativa, buscando superar a classificação dicotômica de rural e de urbano (CHAMPION; HUGO, 2003; MONTEIRO; CARDOSO, 2012). Na Região Norte, a ocupação da "fronteira agrícola”, nos anos 1960 e 1970, está ligada à urbanização (BECKER, 1985, 1995). Quatro décadas depois, esta "floresta urbanizada” (BECKER, 1995) parece se aproximar da "urbe amazônida” (BECKER, 2013), constituindo-se por uma rede urbana que conecta áreas consideradas rurais, pequenas, médias e grandes cidades (GUEDES; COSTA; BRONDIZIO, 2009), com destaque para as médias (SATHLER; MONTE-MÓR; CARVALHO, 2009). ${ }^{1}$

$\mathrm{Na}$ rede de cidades da Amazônia se combinam antigos aglomerados, geralmente distribuídos ao longo dos rios, centros próximos às estradas e aos projetos de colonização criados durante o regime militar e cidades mais recentes. Muitos dos lugares onde hoje se observam cidades aparecem como floresta nas imagens de satélite do início dos anos 1970. Diferentes municípios apresentam processos distintos de conversão de usos e coberturas florestais e de pasto em uso urbano (RAMOS, 2014, p. 122-123).

No Pará, com o estímulo do governo federal, essa transição de usos-coberturas da terra se deu pela urbanização associada aos projetos de colonização, como no caso da Transamazônica: núcleos urbanos hierárquicos (agrovilas) que orientavam a ocupação e se articulavam com o uso do meio rural (BECKER, 1995). Outras cidades se estruturam a partir de lotes rurais que, progressivamente, perderam seus usos agropecuários e passaram a concentrar pessoas, infraestruturas e serviços. Mais "espontâneas", ou, pelo menos, não planejadas pelo Estado, tais concentrações aproximam-se do que se poderia definir como uma forma de urbanização in situ (in situ urbanization), em que assentamentos rurais se transformam em urbanos sem depender, necessariamente, do deslocamento da população em longas distâncias (ZHU, 2004). ${ }^{2}$

\footnotetext{
${ }^{1}$ Segundo Becker (2013), os núcleos urbanos constituíram a base logística para a expansão das fronteiras na Amazônia, formando uma fronteira urbanizada, e atualmente a proliferação de núcleos urbanos com reduzido tamanho funciona como local de refúgio e resistência de populações expropriadas da terra; porém trata-se de núcleos urbanos com diversas carências e com dificuldade de criar e manter uma estrutura econômica que possa garantir o desenvolvimento local e a aliança entre desenvolvimento econômico e conservação ambiental.

20 termo é geralmente aplicado àquele processo de urbanização na China que se dá pela conversão de assentamentos rurais e não pela intensa migração do rural ao urbano. Sobre o caso chinês, ver ZHU et al. (2009).
} 
Dispostas espacialmente nessa rede, as Unidades de Conservação e as Terras Indígenas constituem um componente importante no quadro amplo das configurações de rurais e de urbanos que se articulam. Por um lado, a crescente conectividade da rede pode causar impactos como a fragmentação de unidades de conservação e de ecossistemas (GUEDES; COSTA; BRONDIZIO, 2009). Por outro, os limites de tais unidades podem funcionar como barreiras à conectividade. Sathler, Monte-Mór e Carvalho (2009) argumentam que a rede urbana na Amazônia apresenta dificuldades (fragilidades) que restringem ou impedem os fluxos de pessoas, tais como as grandes distâncias entre os centros menores e as capitais e a carência de infraestrutura de transporte, entre outros aspectos. Pelos possíveis impactos tanto das APs na rede quanto da rede nas APs, a bibliografia aponta para a necessidade de incluir estudos de populações em Áreas Protegidas na discussão mais abrangente sobre distribuição da população e urbanização.

Para os estudos populacionais, particularmente os de população e ambiente, o interesse em Áreas Protegidas se dá a partir dos seus significados para a redistribuição da população. De uma perspectiva regional, em tais unidades estão as porções que se pretende apartar das dinâmicas de ocupação predominantes. Do ponto de vista local, as APs definem regras de ocupação e de usos que impactam as dinâmicas e a distribuição da população em cada unidade e entorno. No caso das Terras Indígenas e de determinadas Unidades de Conservação de Uso Sustentável, como as Reservas Extrativistas, acrescenta-se que as unidades são sinal de reconhecimento de formas de ocupação (e de usos) que precedem e/ou se colocam alternativamente.

\section{População em Áreas Protegidas}

Os espaços reservados à conservação ambiental e/ou destinados à ocupação de populações tradicionais, indígenas ou quilombolas podem ser chamados de Áreas Protegidas (MEDEIROS, 2006). Essas áreas estão enquadradas nos Espaços Territoriais Especialmente Protegidos (PEREIRA; SCARDUA, 2008, p. 90-91), que abrigam: as Unidades de Conservação; as áreas destinadas às comunidades tradicionais (Terras Indígenas e Territórios Quilombolas); as áreas tombadas; os monumentos arqueológicos e pré-históricos; as áreas especiais e locais de interesse turístico; as reservas da biosfera; os corredores ecológicos; e as zonas de amortecimento. Por sua dimensão e número de unidades, optamos por considerar aqui as Áreas Protegidas conhecidas como Unidades de Conservação (UC) e as Terras Indígenas ( $\mathrm{TI})$.

As Unidades de Conservação, sejam municipais, estaduais ou federais, estão enquadradas no Sistema Nacional de Unidades de Conservação da Natureza do Brasil - SNUC (BRASIL, 2000), em dois grupos: Proteção Integral (PI) - unidades onde a presença de população humana, seja para residência ou mesmo para visitação, é expressamente desencorajada, restringida e até proibida; e Uso Sustentável (US) - espaços onde a existência de moradores é permitida e em alguns casos torna-se uma condição. 
Existem duas vertentes que polarizam a ideia de população humana em Áreas Protegidas: uma entende que a população é uma ameaça e não deve entrar em contato com recursos dessas áreas; e outra encara a população como uma potencialidade, como uma das ferramentas da gestão ambiental. De acordo com Carneiro da Cunha e Almeida (2009, p. 285-6), a primeira vertente prevalece no modelo norte-americano de Yellowstone, que criava ambientes intocados sem população humana. No Brasil, tanto nas TIs quanto nas UCs - sobretudo as de uso sustentável -, prevalece a ideia de que as populações devem proteger o ambiente e os recursos podem ser utilizados para sustentar seus modos de vida, o que reflete a noção de que as populações não são vítimas e sim parceiras das preocupações ambientais.

As Terras Indígenas são aquelas tradicionalmente ocupadas pelos povos indígenas, habitadas em caráter permanente ou utilizadas para suas atividades produtivas ou para garantir seu bem-estar e sua reprodução física e cultural, segundo seus usos, costumes e tradições. Tais áreas estão sob responsabilidade da Fundação Nacional do Índio (Funai), órgão subordinado ao Ministério da Justiça do Brasil. Anteriormente chamadas de Reservas Indígenas, estas áreas implicam a presença da população indígena que habita ou utiliza as terras (BRASIL, 1988, artigo 231).

Segundo Diegues (2004), existe certo consenso em torno da expressão "população indígena", indicando etnia e agregando os povos que guardam uma continuidade histórica e cultural desde antes da conquista europeia da América. 0 consenso parece não existir em relação à definição de populações tradicionais. Aquelas residentes ou que utilizam as Unidades de Conservação podem ser chamadas de "populações tradicionais", embora também possam ser denominadas, sobretudo em documentos de organismos internacionais, como é o caso da OIT (1989), como povos nativos ou tribais. A Lei n. 9.985, que cria o SNUC (BRASIL, 2000), não define o que são populações tradicionais, embora seu artigo 5 - permita entender que se trata de pessoas que dependem da utilização de recursos que estão no interior das UCs e que, com a delimitação de uma unidade, terão que ser indenizadas ou abastecidas por recursos alternativos.

Para fins deste trabalho, as pessoas situadas em UC e TI são denominadas população residente. 0 caráter de residência parece ser apropriado por diversos motivos: em termos de estatísticas oficiais, o termo é útil, pois as pesquisas domiciliares, como o Censo Demográfico, são baseadas no conceito de população residente; em termos jurídicos, o Decreto n, 4.340 (BRASIL, 2002), que regulamenta o SNUC (BRASIL, 2000), já admite a denominação populações residentes; em termos antropológicos, população residente tem um sentido mais genérico e de conteúdo menos denso do que o termo tradicional (WEST; BRECHIN, 1991 apud BARRETTO FILHO, 2006, p. 138) - aplicando-se melhor à existência de outros residentes permanentes ou eventuais que não se identificam como indígenas e nem se consideram tradicionais. Cabe destacar que, pela própria forma de uso e de ocupação da população em APs, sabe-se que dentro delas existem várias áreas desabitadas que não são utilizadas para residência, mas sim como área de trânsito ou como fonte de recursos - inclusive para pessoas de fora das unidades. 


\section{População, ambiente e espaço}

O interesse em relacionar a distribuição da população com usos e coberturas da terra em Áreas Protegidas, no quadro mais amplo do Pará, remete aos desafios das análises espaciais nos estudos populacionais.

Para alguns autores, a demografia tem uma longa tradição espacial (VOSS, 2007), a qual significa, de fato, apenas uma consciência do espaço (WEEKS, 2004). Tal consciência se observa, por exemplo, em estudos comparativos de características demográficas entre contextos diferentes, em estudos de migração e nas explicações que circunscrevem espacialmente o declínio da fecundidade e as diferenças nas taxas de mortalidade (CASTRO, 2007). Tradicionalmente, os estudos populacionais exploram a dimensão temporal em suas análises, colocando o tempo em termos de idade, período e coorte, ${ }^{3}$ mas não fazem o mesmo, com igual intensidade, em relação ao espaço (MOUW, 2000).

As análises se sofisticaram nas últimas décadas pela incorporação de dados digitais e espaciais, assim como pelo uso de ferramentas como os Sistemas de Informações Geográficas (SIG). Mapas contendo variáveis demográficas se tornaram potentes instrumentos que revelam padrões imperceptíveis nas tabelas convencionais. Contudo, para que o espaço seja analiticamente incorporado aos estudos de população, faz-se necessária a criação de modelos que explicitem as relações entre o espaço e os fenômenos demográficos, o que ainda se revela como uma das maiores dificuldades (NICHD, 2002).

Associada a esta dificuldade analítica, existe a limitação relativa ao modo como as variáveis de população são apresentadas. Os dados censitários são geralmente disseminados em unidades de área (polígonos), que expressam unidades operacionais ou estatísticas, como os setores censitários e as áreas de ponderação, ou administrativas, como os municípios. Além dos problemas inerentes a qualquer análise baseada em unidades de área, como MAUP e Falácia Ecológica, ${ }^{4}$ o uso de limites administrativos e/ou operacionais traz uma série de restrições, tais como: baixa resolução espacial; falta de aderência aos limites de outras camadas de informação; e alterações nos seus limites ao longo do tempo (BUENO, 2014). 0 uso de tais unidades não favorece a realização de análises espaciais, restringindo a articulação dos dados demográficos a outros conjuntos de informações (GRASLAND; MADELIN, 2006; DE SHERBININ et al., 2002).

A grade estatística, um sistema de células regulares que servem como repositório para dados estatísticos georreferenciados (TRAINOR, 2010), oferece algumas vantagens em relação às formas de disseminação de dados agregados baseadas em setores censi-

\footnotetext{
${ }^{3} 0$ efeito de idade corresponde aos processos biológicos, psicológicos e sociais ao longo da evolução humana ou a cada faixa etária; o efeito de período reflete mudanças que atingem toda a população, como as ambientais, econômicas e sociais; os efeitos de coorte podem refletir mudanças entre um grupo de indivíduos com a mesma idade (GUIMARÃES; RIOS-NETO, 2011).

${ }^{4}$ No Modifiable Area Unit Problem ou MAUP (OPENSHAW, 1984), ocorrem, pelos efeitos de escala e de zoneamento, a diminuição da variância dos resultados obtidos e a consequente perda de heterogeneidade, conforme variam as unidades de análise (GEHLKE; BIEHL, 1934; OPENSHAW; TAYLOR, 1979, 1981; WONG, 1996). A Falácia Ecológica é um erro inferencial, que faz com que uma análise baseada em dados agregados leve a conclusões diferentes daquelas que seriam obtidas com a análise dos dados individuais (ROBINSON, 1950).
} 
tários ou municípios. Pequenas em comparação às outras unidades, as células oferecem melhor resolução espacial e, consequentemente, melhor adaptação a outras camadas de informação (GUZMÁN; SCHENSUL; ZHANG, 2013). A grade permite abstrair limites político-administrativos, o que lhes atribui estabilidade temporal, uma vez que as células não variam ao longo do tempo. 0 sistema é mais adequado à interpretação cartográfica temática e possibilita transitar desde recortes intraurbanos até unidades da federação ou país. As células facilitam a execução de modelagens e, de acordo com vários autores, seu uso pode minimizar os efeitos do MAUP (GOODCHILD, 1992; SCHUURMAN et al., 2006; CARVALHO et al., 2004). ${ }^{5}$

Apesar de o uso de grades estatísticas contribuir para uma melhor percepção das relações recíprocas entre as variáveis sociodemográficas e as ambientais em estudos das dinâmicas de uso e cobertura da terra, as técnicas de desagregação normalmente utilizadas para transferir os dados censitários para as células requerem dados auxiliares com resolução alta (TATEM et al., 2007) - sejam eles classificações utilizando imagens de satélite ou mapeamento de vias ou edificações - e modelos de distribuição dos dados adequados e calibrados com a realidade local. Optou-se, neste trabalho, por uma abordagem híbrida (BUENO, 2014) que prioriza técnicas de agregação de dados, conforme descrição a seguir.

\section{Montagem da grade}

Em um Sistema de Informações Geográficas (SIG) foi montada a grade estatística utilizada neste trabalho para integrar as variáveis do Censo Demográfico àquelas relativas aos usos e coberturas da terra e às Áreas Protegidas consideradas.

A grade estatística contém células com 37,5 arcos segundos de medida lateral, o equivalente no Equador a 1.152 metros (BUENO, 2014). A dimensão das células foi definida de acordo com o Sistema Cartográfico Nacional estendido ao Mapeamento Cadastral, de forma que as células pudessem coincidir com mapas na escala 1:2000. Considerando-se todo o Estado do Pará, a grade possui 941.850 células, o que oferece uma resolução espacial média de $1,15 \mathrm{~km}$, bastante superior àquela da malha de setores censitários, que é de $11,82 \mathrm{~km} .^{6}$

A transferência dos dados do Universo do Censo Demográfico 2010 (população residente, domicílios ocupados e situação do domicílio) para a grade estatística se deu por

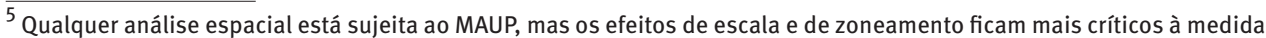
que a quantidade de unidades diminui e a dimensão das unidades aumenta (WRIGLEY, 1995). Ainda que não seja unânime a afirmação de que a agregação de dados em níveis geográficos menores minimize os impactos do MAUP (OPENSHAW; RAO, 1995), a estratégia é defendida por Goodchild (1992) e Schuurman et al. (2006), entre outros. Como um sistema de grade estatística apresenta uma grande quantidade de células pequenas, ao contrário de um sistema de unidades administrativas com poucas unidades de grande extensão, infere-se que o MAUP é menos crítico no primeiro caso.

${ }^{6}$ A resolução espacial média pode ser calculada pela extração da raiz quadrada do quociente entre a área de uma região e o número de unidades que compõem esta região (TOBLER, 1997, p. 206-207). No Estado do Pará, de acordo com o Censo Demográfico 2010, existiam 8.933 setores censitários. Considerando-se uma área total de $1.247 .995 \mathrm{~km} 2$, obtém-se a resolução espacial média de $11,82 \mathrm{~km}$.
} 
uma abordagem híbrida definida por Bueno (2014), que combina técnicas de agregação e de desagregação.

A abordagem de agregação se deu por incorporação direta de pontos (coordenadas dos domicílios), incorporação de faces de quadra e incorporação direta de setor censitário (BUENO, 2014). Tal abordagem foi priorizada por sua simplicidade e por ser supostamente mais precisa, uma vez que se dá pela transferência direta dos dados. Contudo, sua implementação depende da existência de informações georreferenciadas (coordenadas geográficas dos domicílios) e das condições de acesso a tais dados, geralmente restritos às agências oficiais responsáveis pela execução dos censos. No Brasil, a adoção de geotecnologias na operação censitária, como a utilização de dispositivos de coleta dos dados com GPS e a associação do Cadastro Nacional de Endereços para Fins Estatísticos (CNEFE) com a geometria das vias, possibilitou o uso da abordagem de agregação para boa parte dos dados coletados no Censo 2010, mas não para todo o seu conjunto. ${ }^{7}$

Utilizada nas situações em que a agregação não foi possível, a abordagem de desagregação engloba técnicas que transferem os dados existentes em uma unidade espacial para outra, por meio da criação de um denominador espacial comum entre essas unidades (PLUMEJEAUD et al., 2010). Algumas das técnicas pertencentes a este tipo de abordagem são conhecidas e utilizadas há bastante tempo e surgiram, principalmente, para resolver o problema de incompatibilidade entre áreas para as quais as estatísticas oficiais são publicadas e aquelas para as quais se deseja ter essas informações.

A Tabela 1 sintetiza a abordagem híbrida utilizada para a incorporação de dados censitários à grade estatística do Estado do Pará. As técnicas de agregação foram empregadas em $81,72 \%$ dos setores censitários, enquanto as de desagregação foram utilizadas nos casos em que a agregação não foi possível (18,28\% do total de setores censitários). As operações efetuadas geraram uma perda de $3,8 \%$ dos domicílios ocupados e da população residente no Pará, comparativamente aos dados oficiais divulgados pelo IBGE (2011b). A perda pode ser considerada como distribuída em todo o estado e entendida como aceitável, tendo em vista a maior acurácia e a melhor resolução espacial que a grade estatística oferece comparativamente ao que se obtém com a utilização dos setores censitários.

Os dados de uso e cobertura da terra de 2010 incorporados às células da grade são provenientes do projeto TerraClass (INPE, 2011). De acordo com a classificação adotada pelo Inpe, cada polígono corresponde a uma das 16 categorias de uso e cobertura, as quais foram agrupadas em oito categorias para o presente estudo: área urbana; mosaico (uma classe mista, originalmente definida pelo Inpe, em que não se pode definir uma cobertura/ uso dominante); agricultura; hidrografia; regeneração; pasto; vegetação; e outros. Realizou-se a interseção espacial da grade estatística com a camada contendo as oito classes de uso e cobertura da terra e, então, foi calculado o percentual de área de cada classe em relação à área total de cada célula.

\footnotetext{
${ }^{7}$ A partir do trabalho desenvolvido por Bueno (2014), com dados cedidos pelo IBGE, o uso de grades para disseminação de dados oficiais está em estudo por parte do Instituto.
} 
TABELA 1

Setores censitários, segundo abordagem híbrida de agregação e desagregação de dados Estado do Pará - 2010

\begin{tabular}{|c|c|c|}
\hline \multirow{2}{*}{ Abordagens } & \multicolumn{2}{|c|}{ Setores censitários } \\
\hline & $\mathrm{N}$ & $\%$ \\
\hline $\begin{array}{l}\text { Abordagem de agregação } \\
\text { (abordagem prioritária, executada pela incorporação direta dos dados) }\end{array}$ & 7.166 & 81,72 \\
\hline $\begin{array}{l}\text { Técnica } 1 \text { - Incorporação direta de pontos } \\
\text { Aplicada em áreas estritamente rurais, para as quais existem as coordenadas } \\
\text { geográficas dos domicílios visitados pelo censo. Os dados estatísticos foram associados } \\
\text { aos pontos dos domićlios e estes foram agregados às células (BUENO, 2014). }\end{array}$ & 2.154 & 24,56 \\
\hline $\begin{array}{l}\text { Técnica } 2 \text { - Incorporação de faces de quadra } \\
\text { Aplicada em áreas urbanas, utilizando os códigos presentes tanto no cadastro de } \\
\text { endereços como no mapeamento censitário para localizar os domicílios nas faces de } \\
\text { quadra. A distribuição dos domicílios foi considerada uniforme na extensão da face } \\
\text { (BUENO, 2014). }\end{array}$ & 4.843 & 55,23 \\
\hline $\begin{array}{l}\text { Técnica } 3 \text { - Incorporação direta de setor censitário } \\
\text { Aplicada aos setores censitários com dimensões menores que as células da grade e } \\
\text { que estão totalmente contidos em uma única célula ou que possuem pelo menos 90\% } \\
\text { da superfície dentro da célula (BUENO, 2014). }\end{array}$ & 169 & 1,93 \\
\hline $\begin{array}{l}\text { Abordagem de desagregação } \\
\text { (abordagem complementar adotada em situações em que a agregação não foi possível) }\end{array}$ & 1.603 & 18,28 \\
\hline $\begin{array}{l}\text { Técnica } 4 \text { - Método dasimétrico com malha viária } \\
\text { A malha viária foi utilizada como uma aproximação para a distribuição de domicílios e } \\
\text { para realizar a transformação da população agregada por setor censitário em células } \\
\text { (XIE, 1995; MROZINSKI; CROMLEY, 1999; REIBEL; BUFALINO, 2005; BRINEGAR; POPICK, } \\
\text { 2010). Esta técnica foi utilizada em áreas urbanizadas com disponibilidade de malha } \\
\text { viária detalhada. }\end{array}$ & 1.100 & 12,54 \\
\hline $\begin{array}{l}\text { Técnica } 5 \text { - Método dasimétrico com classificação de uso/cobertura da terra } \\
\text { Os dados de classificação de uso/cobertura das terras com base em imagens orbitais } \\
\text { foram utilizados como uma aproximação para a distribuição dos domicílios em áreas } \\
\text { não urbanizadas (EICHER; BREWER, 2001; LANGFORD; UNWIN, 1994; HOLT et al., 2004). }\end{array}$ & 450 & 5,13 \\
\hline $\begin{array}{l}\text { Técnica } 6 \text { - Ponderação zonal } \\
\text { A ponderação zonal simples foi aplicada para transformar os dados de setores } \\
\text { censitários para dados em células, conforme a área de cada setor censitário (RASE, } \\
\text { 2001; REIBEL; AGRAWAL, 2007). }\end{array}$ & 53 & 0,60 \\
\hline Total & 8.769 & 100,00 \\
\hline
\end{tabular}

Fonte: Adaptado de Bueno (2014).

Por fim, por meio de uma junção espacial, os atributos de cada uma das Áreas Protegidas do Pará foram transferidos para as células correspondentes: nome; tipo (UC ou TI); grupo (PI ou US); categoria (tais como Reserva Extrativista, Parque, etc.) e ano de criação.

O Plano de Informação das Áreas Protegidas, com os limites e as características em formato shapefile, foi adquirido por meio da base de dados do Ministério do Meio Ambiente (BRASIL, s/d). Foram selecionadas as APs do Estado do Pará criadas até 2010, as quais somam um conjunto de 113 unidades (Tabela 2): 46 Terras Indígenas; 16 Unidades de Conservação (UC) de Proteção Integral, mais restritas à presença humana, divididas entre as categorias Estação Ecológica (Esec), Parque Estadual (PE), Parque Nacional (Parna), Refúgio da Vida Silvestre (RVS), Reserva Biológica (Rebio); e 51 UC de Uso Sustentável, menos restritas à presença humana, divididas em Área de Proteção Ambiental (APA), Floresta Estadual (FE), Floresta Nacional (Flona), Reserva de Desenvolvimento Sustentável (RDS) e Reserva Extrativista (Resex). 
A seleção das Tls no Pará incluiu as unidades regularizadas até 31 de dezembro de 2010, em conformidade com os critérios adotados pelo IBGE (2012, p. 16-17), e que possuíam informação de limites territoriais fornecidos pela Funai. Em sete casos de sobreposição de partes de Terras Indígenas e Unidades de conservação, as partes duplicadas foram atribuídas a apenas uma das unidades. ${ }^{8}$

TABELA 2

Esfera de poder, áreas oficial e recalculada e quantidade de unidades, segundo tipos de Áreas Protegidas

Estado do Pará - 2010

\begin{tabular}{|c|c|c|c|c|c|}
\hline Áreas Protegidas & Categoria & Esfera & $\begin{array}{l}\text { Área }\left(\mathrm{km}^{2}\right) \\
\text { (1) }\end{array}$ & $\begin{array}{c}\text { Área } \\
\text { recalculada } \\
\left(\mathrm{km}^{2}\right)(2)\end{array}$ & Unidades \\
\hline Terra Indígena (3) & - & Federal & $283.383,08$ & $283.383,08$ & 46 \\
\hline \multirow{7}{*}{$\begin{array}{l}\text { UC } \\
\text { Proteção Integral }\end{array}$} & \multirow[t]{2}{*}{ Estação Ecológica (Esec) } & Estadual & $42.025,30$ & $42.025,30$ & 1 \\
\hline & & Federal & $35.368,53$ & $35.368,53$ & 2 \\
\hline & Parque Estadual (PE) & Estadual & 972,17 & 322,45 & 4 \\
\hline & Parque Nacional (Parna) & Federal & $29.374,05$ & $28.457,94$ & 4 \\
\hline & Refúgio da Vida Silvestre (RVS) & Estadual & 63,69 & 63,69 & 1 \\
\hline & \multirow[t]{2}{*}{ Reserva Biológica (Rebio) } & Estadual & $11.697,19$ & $11.471,19$ & 1 \\
\hline & & Federal & $8.492,26$ & $8.492,26$ & 3 \\
\hline \multirow{7}{*}{$\begin{array}{l}\text { UC } \\
\text { Uso Sustentável }\end{array}$} & \multirow[t]{2}{*}{ Área de Proteção Ambiental (APA) } & Estadual & $68.550,42$ & $68.550,42$ & 8 \\
\hline & & Federal & $20.836,35$ & $20.836,35$ & 2 \\
\hline & Floresta Estadual (FE) & Estadual & $78.197,37$ & 78.197,37 & 4 \\
\hline & Floresta Nacional (Flona) & Federal & $64.686,17$ & $63.476,38$ & 14 \\
\hline & \multirow{2}{*}{$\begin{array}{l}\text { Reserva de Desenv. Sustentável } \\
\text { (RDS) }\end{array}$} & Estadual & 516,30 & - & 2 \\
\hline & & Federal & 644,42 & 644,42 & 1 \\
\hline & Reserva Extrativista (Resex) & Federal & $43.604,12$ & $43.604,12$ & 20 \\
\hline Total & & & $688.411,42$ & $684.893,50$ & 113 \\
\hline
\end{tabular}

Fonte: Brasil (s/d). Dados processados pelos autores.

(1) Área conforme consta em Brasil (s/d).

(2) Área resultante da subtração de porções de Unidades de Conservação sobrepostas a TI: TI Andirá-Marau e Parna da Amazônia (-916 km² do Parna); Flona Tapajós sobreposta às Tls Bragança-Marituba e Munduruku-Taquara (-388 km² da Flona); TI Rio Paru d'Este e Rebio de Maicuru (-226 km² da Rebio); TI Trocará - Doação $(0,14$ km²) englobada nas células da TI Trocará; PE Charapucu integrada à APA do Arquipélago do Marajó; RDS Pucuruí-Ararão e RDS Alcobaça incorporadas como parte da APA do Lago de Tucuruí; Flona Itacaiunas possui sobreposição com a Flona Tapirapé-Aquiri (-821,6 km² desta última).

(3) Incluem-se três TIs criadas antes do Censo 2010, mas não consideradas pelo IBGE: Bragança-Marituba, Munduruku-Taquara e Praia do Mangue.

\section{Distribuição da população no Pará - o papel das Áreas Protegidas}

A Tabela 3 contém uma síntese dos resultados da interseção da grade estatística com os limites das áreas protegidas e os dados censitários. Aproximadamente $56 \%$ das células de todo o Pará estão em Áreas Protegidas (cerca de 23\% em TI, 23\% em US e 10\% em PI). Entre as US, predominam as do grupo Florestas (Nacionais e Estaduais) e, entre as $\mathrm{PI}$, as Esec. A participação das Áreas Protegidas na população do estado é relativamente

\footnotetext{
${ }^{8}$ Existem diversos casos documentados de sobreposição de Áreas Protegidas que ocorrem, segundo Rolla e Ricardo (2004), pela falta de conhecimento das condições locais e pelo desrespeito ao direito das populações.
} 
pequena, abrigando apenas $11,5 \%$ dos habitantes do Pará. Porém, trata-se de mais de 800 mil pessoas, a maioria residindo em Áreas de Proteção Ambiental (APA), a categoria que menos restringe a presença humana. As TIs respondem por $0,6 \%$ da população do estado e as unidades de Proteção Integral, geralmente as mais restritivas quanto ao uso e ocupação, por $0,06 \%$.

Ainda na Tabela 3, o coeficiente de Gini da quantidade de domicílios ocupados por célula sintetiza a considerável concentração da população no Pará. Quando são computadas todas as células (inclusive as sem domicílios), os coeficientes são próximos ou superiores a 0,9 em todas as APs, no total do Pará e no subconjunto de células rurais, refletindo a já mencionada presença de população residente em um pequeno número de células. Excluindo-se as células sem domicílios, percebe-se melhor a distribuição da população nas células com domicílios: os coeficientes se reduzem expressivamente nas APs, especialmente nas de Proteção Integral, indicando uma distribuição menos desigual.

TABELA3

Quantidade e percentual de células com domicílios, participação da população e das células no total do estado e coeficiente de Gini, segundo localização das células em relação às Áreas Protegidas

Estado do Pará - 2010

\begin{tabular}{|c|c|c|c|c|c|c|c|c|}
\hline \multirow{3}{*}{ Localização } & \multicolumn{3}{|c|}{ Células } & \multirow{3}{*}{$\begin{array}{l}\text { População } \\
\text { (hab.) }\end{array}$} & \multirow{3}{*}{$\begin{array}{l}\text { População } \\
\text { (2) (\%) }\end{array}$} & \multirow{3}{*}{$\begin{array}{l}\text { Células (2) } \\
\text { (\%) }\end{array}$} & \multicolumn{2}{|c|}{ Gini (3) } \\
\hline & \multirow[t]{2}{*}{ Total } & \multicolumn{2}{|c|}{ Com domicílios } & & & & \multirow{2}{*}{$\begin{array}{l}\text { Todas as } \\
\text { células }\end{array}$} & \multirow{2}{*}{$\begin{array}{l}\text { Células com } \\
\text { domicílios (1) }\end{array}$} \\
\hline & & $\mathrm{N}(1)$ & $\%$ & & & & & \\
\hline Pará exceto AP & 415.074 & 77.767 & 18,736 & 6.455 .936 & 88,470 & 44,070 & 0,981 & 0,901 \\
\hline $\begin{array}{l}\text { Pará somente AP } \\
\text { (UC e TI) }\end{array}$ & 526.776 & 15.099 & 2,866 & 841.416 & 11,530 & 55,930 & 0,996 & 0,848 \\
\hline Terras Indígenas & 218.353 & 1.469 & 0,673 & 44.653 & 0,612 & 23,183 & 0,998 & 0,732 \\
\hline $\begin{array}{l}\text { UC de Proteção } \\
\text { Integral }\end{array}$ & 95.389 & 210 & 0,220 & 4.388 & 0,06 & 10,128 & 0,999 & 0,687 \\
\hline Estação Ecológica & 58.304 & 22 & 0,038 & 105 & 0,001 & 6,190 & 1,000 & 0,409 \\
\hline Parques (4) & 21.789 & 68 & 0,312 & 855 & 0,012 & 2,313 & 0,999 & 0,574 \\
\hline $\begin{array}{l}\text { Refúgio da Vida } \\
\text { Silvestre }\end{array}$ & 72 & 19 & 26,389 & 707 & 0,010 & 0,008 & 0,894 & 0,597 \\
\hline Reserva Biológica & 15.224 & 101 & 0,663 & 2.721 & 0,037 & 1,616 & 0,998 & 0,710 \\
\hline $\begin{array}{l}\text { UC de Uso } \\
\text { Sustentável }\end{array}$ & 213.034 & 13.420 & 6,299 & 792.375 & 10,858 & 22,619 & 0,991 & 0,855 \\
\hline $\begin{array}{l}\text { Área de } \\
\text { Preservação } \\
\text { Ambiental }\end{array}$ & 70.162 & 10.581 & 15,081 & 635.702 & 8,711 & 7,449 & 0,979 & 0,86 \\
\hline Florestas (5) & 108.359 & 629 & 0,580 & 46.634 & 0,639 & 11,505 & 0,999 & 0,903 \\
\hline $\begin{array}{l}\text { Reserva } \\
\text { de Desenv. } \\
\text { Sustentável }\end{array}$ & 547 & 54 & 9,872 & 1.303 & 0,018 & 0,058 & 0,948 & 0,472 \\
\hline $\begin{array}{l}\text { Reservas } \\
\text { Extrativistas }\end{array}$ & 33.966 & 2.156 & 6,348 & 108.736 & 1,490 & 3,606 & 0,987 & 0,798 \\
\hline Total do Pará & 941.850 & 92.866 & 9,86 & 7.297.352 & 100,000 & 100,000 & 0,990 & 0,895 \\
\hline
\end{tabular}

Fonte: IBGE. Censo Demográfico 2010; Bueno (2014).

(1) Domicílios ocupados.

(2) Em relação ao total do Estado do Pará.

(3) Coeficiente de Gini da quantidade de domicílios ocupados por célula.

(4) Parques Nacionais e Estaduais.

(5) Florestas Nacionais e Estaduais.

Nota: Dados integrados à grade estatística com 941.850 células de 37,5 arcos segundo em todo o Estado do Pará. 
Fazendo uma aproximação do que se pode classificar como urbano, conforme tipologia do IBGE incorporada à grade, observa-se na Tabela 4 que as células urbanas têm pequena participação no conjunto do estado (0,33\%), mas grande participação em sua população total (71,6\%). Excluindo-se as células urbanas em APs, percebe-se redução de cerca de $10 \%$ no total de células ( 2.793 em 3.109 células) e de habitantes - o que indica que as Áreas Protegidas não se resumem a ocupações não urbanas. 0 coeficiente de Gini da quantidade de domicílios ocupados por célula indica que a concentração se dá dentro e fora das APs.

TABELA 4

Quantidade e percentual de células com domicílios, participação da população e das células no total do estado e coeficiente de Gini, segundo localização das células em relação à situação do domicílio Estado do Pará - 2010

\begin{tabular}{|c|c|c|c|c|c|c|c|c|}
\hline \multirow{3}{*}{ Localização } & \multicolumn{3}{|c|}{ Células } & \multirow{3}{*}{$\begin{array}{c}\text { População } \\
\text { (hab.) }\end{array}$} & \multirow{3}{*}{$\begin{array}{c}\text { População } \\
\text { (2) (\%) }\end{array}$} & \multirow{3}{*}{$\begin{array}{l}\text { Células } \\
\text { (2) (\%) }\end{array}$} & \multirow{2}{*}{\multicolumn{2}{|c|}{ Gini (3) }} \\
\hline & \multirow[b]{2}{*}{$\begin{array}{l}\text { Total } \\
\text { (N) }\end{array}$} & \multicolumn{2}{|c|}{ Com domicílios } & & & & & \\
\hline & & $N(1)$ & $\%$ & & & & $\begin{array}{l}\text { Todas as } \\
\text { células }\end{array}$ & $\begin{array}{c}\text { Células com } \\
\text { domicílios (1) }\end{array}$ \\
\hline Pará urbano & 3.109 & 2.398 & 77,131 & 5.193 .051 & 71,163 & 0,330 & 0,784 & 0,720 \\
\hline Exceto AP & 2.793 & 2.162 & 77,408 & 4.688 .448 & 64,249 & 0,297 & 0,784 & 0,721 \\
\hline Pará rural & 938.741 & 90.468 & 9,637 & 2.104 .301 & 28,837 & 99,670 & 0,970 & 0,686 \\
\hline Exceto AP & 412.281 & 75.605 & 18,338 & 1.767 .488 & 24,221 & 43,774 & 0,944 & 0,693 \\
\hline Total do estado & 941.850 & 92.866 & 9,860 & 7.297.352 & 100,000 & 100,000 & 0,990 & 0,895 \\
\hline
\end{tabular}

Fonte: IBGE. Censo Demográfico 2010; Bueno (2014).

(1) Domicílios ocupados.

(2) Em relação ao total do Estado do Pará.

(3) Coeficiente de Gini da quantidade de domicílios ocupados por célula.

Nota: Dados integrados à grade estatística com 941.850 células de 37,5 arcos segundo em todo o estado do Pará.

A constatação de que pouco mais de $90 \%$ da área do estado não contém domicílios ocupados, o que se justifica em larga medida pelas Áreas Protegidas, merece uma ressalva, sobretudo em relação às TIs e UCs de Uso Sustentável. A ausência de domicílios ocupados em uma célula não significa necessariamente ausência de usos, ocupações e sentidos, dimensões não abordadas no artigo, não devendo ser tomada como expressão de um "vazio demográfico". Assim como ocorre com outros tipos de unidade de análise, uma célula não revela possíveis relações da área que representa com áreas e populações representadas em outras células. Por exemplo, uma célula sem domicílios ocupados e com cobertura de floresta, em uma Resex, pode ser utilizada por uma população residente distante dali para extração de recursos florestais não madeireiros.

Voltando-se para os $9,8 \%$ de células com domicílios e separando-as conforme o volume da população residente, tem-se que 50\% da população do Pará está em 9,815\% das células da grade e $50 \%$ da população está no $0,045 \%$ restante. A distribuição desigual se reproduz em outros recortes: $10 \%$ da população do estado está em 0,003\% das células.

0 Gráfico 1, em escala logarítmica, revela que, mesmo que os números de residentes sejam diferentes entre as APs em função de suas regras de uso, o padrão de ocupação das células é semelhante ao que se verifica para o restante do estado - onde as regras de restrição ao uso e ocupação das APs não vigoram. Em linhas gerais, observam-se um grande número de células com poucos residentes e a tendência de diminuição do número de células 
conforme aumenta o número de residentes em cada uma delas. Os volumes populacionais envolvidos podem ser diferentes, mas os padrões de distribuição se assemelham.

GRÁFICO 1

População residente por células, segundo localização

Estado do Pará - 2010
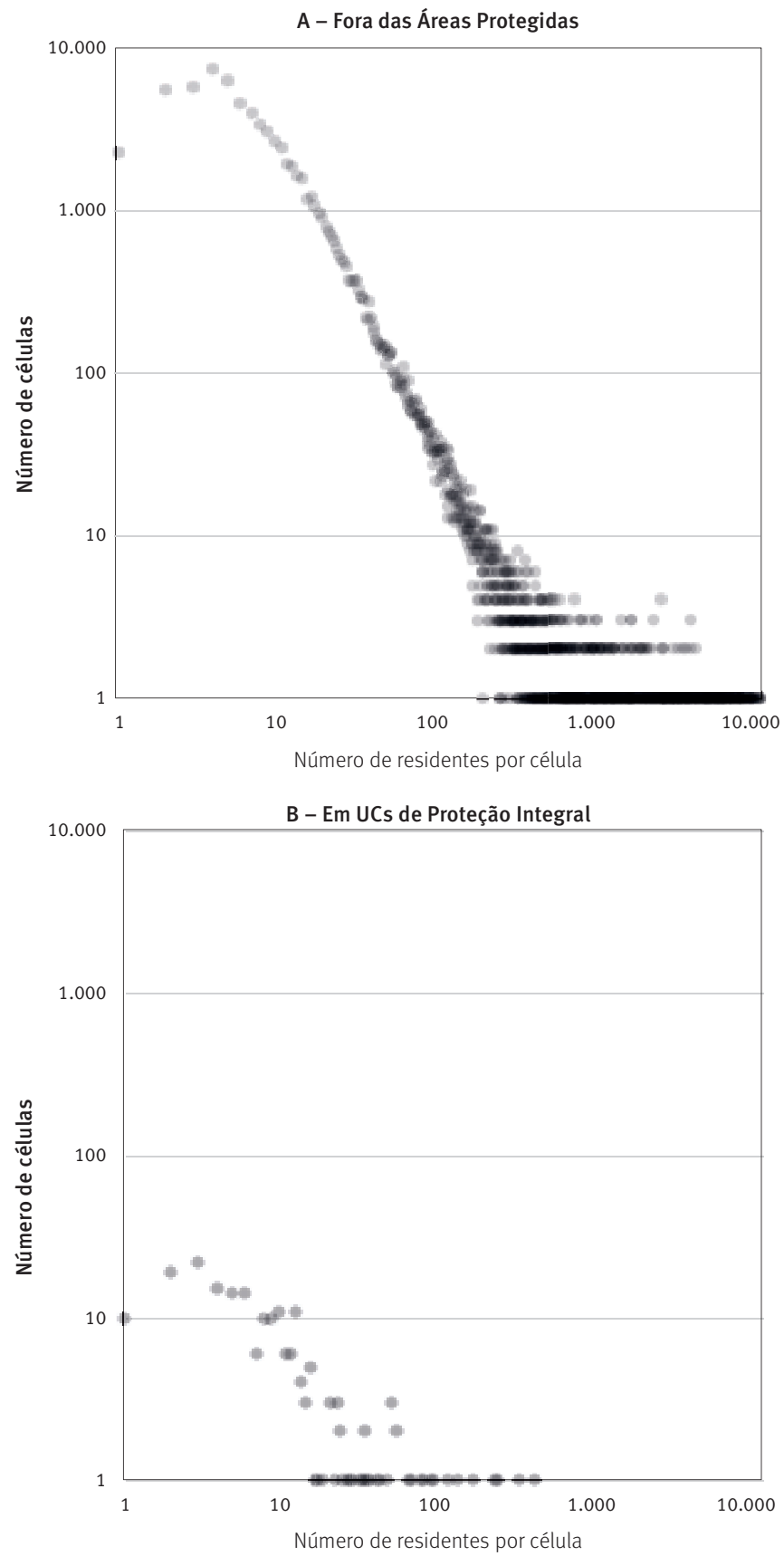

(Continua) 
(continuação)
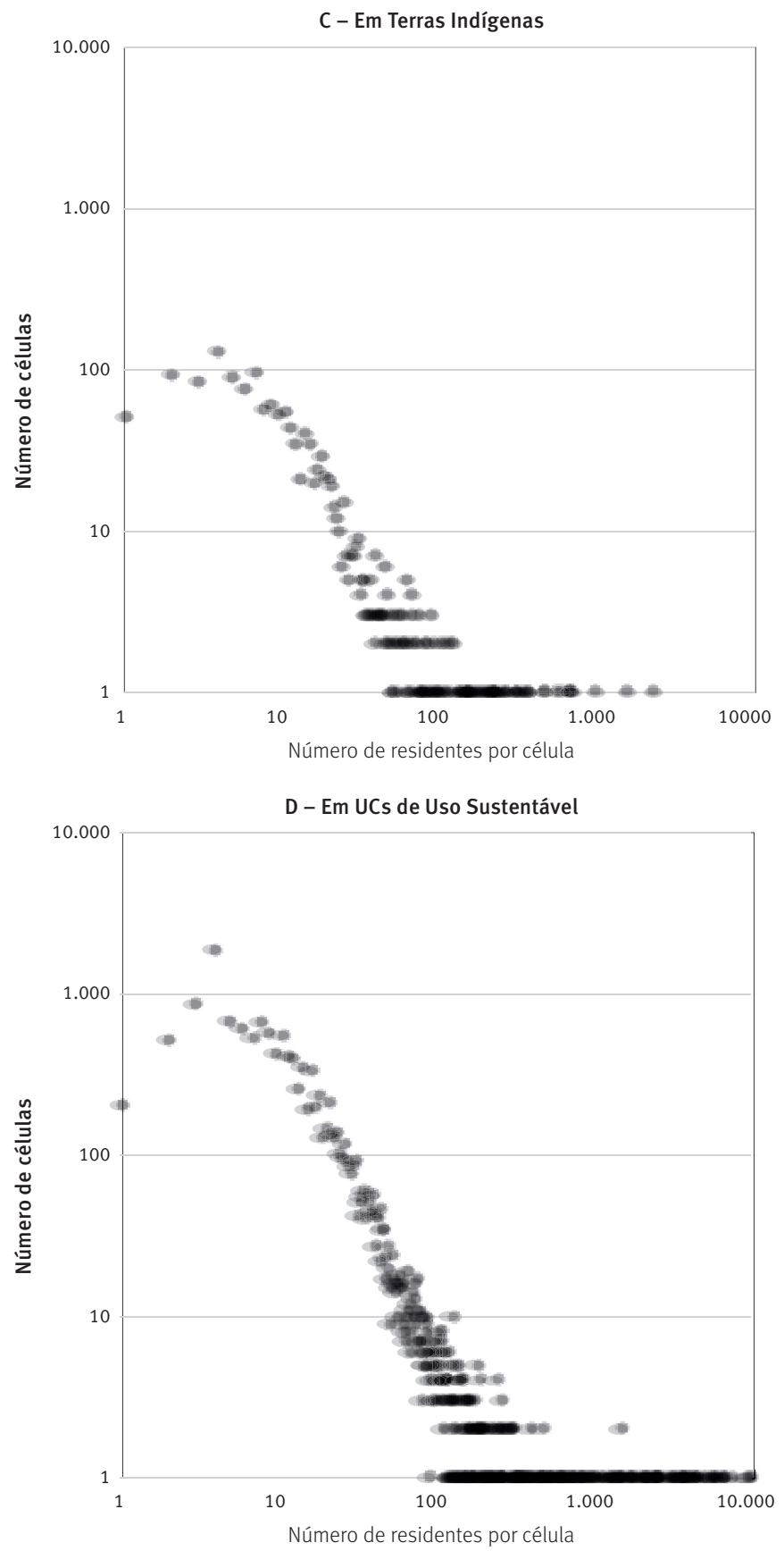

Fonte: IBGE. Censo Demográfico 2010; Bueno (2014).

Nota: Dados processados pelos autores a partir da grade estatística. Cada ponto representa uma ocorrência. Foram consideradas apenas as células com população residente: A - 77.767 células ocupadas em um total de 415.074; B - 210 em 95.389; C - 1.469 em 218.353; D - 13.420 em 213.034. 
Quanto às relações da população com usos e coberturas da terra, segundo dados do TerraClass (INPE, 2011), deve-se levar em conta que os maiores percentuais das classes de uso e cobertura incidem sobre as células sem domicílios ocupados, uma vez que a população se concentra em poucas células (Tabela 5). Por outro lado, as classes mais associadas às formas de ocupação humana são as que possuem os menores percentuais de células sem domicílios: $81 \%$ das células com "área urbana" e 45,3\% das com “mosaico" apresentam população residente. A classe vegetação é a que possui menor percentual de células com domicílios (9,7\%).

Verifica-se uma relação positiva e forte entre volume de população e elevado percentual de área urbana. 0 coeficiente de correlação de Pearson mostra que, quanto maior for a área da célula coberta por área urbana, maior será a população na célula ( $\rho>0,711$ ). As demais correlações não são significativas, embora mostrem uma tendência que se verá com mais força adiante: uma correlação positiva entre volume de população e percentual de "mosaico" e uma correlação negativa entre volume de população e o percentual de "vegetação".

As Áreas Protegidas detêm $57,2 \%$ das células com vegetação, sendo que a maior parte se localiza em TIs; e uma porção significativa (26\%) das células com hidrografia está em TI. Estes dados reforçam a importância das APs para a conservação da natureza. Por outro lado, nas áreas externas às APs, são elevados os percentuais de células com área urbana $(86,4 \%)$, agricultura $(99,5 \%)$, pasto $(90,3 \%)$, regeneração e mosaico (ambas com $88,4 \%$ ). Tais valores são esperados devido aos usos mais intensivos que ocorrem fora das APs (Tabela 6).

TABELA 5

Distribuição das células, por classe de uso e cobertura da terra, segundo situação de ocupação Estado do Pará - 2010

\begin{tabular}{lrrrrrrrr}
\hline \multirow{2}{*}{$\begin{array}{c}\text { Situação de } \\
\text { ocupação }\end{array}$} & \multicolumn{7}{c}{ Classes de uso e cobertura da terra (células) } \\
\cline { 2 - 8 } & Agricultura & $\begin{array}{c}\text { Área } \\
\text { urbana }\end{array}$ & Hidrografia & Mosaico & Outros & Pasto & Regeneração & Vegetação \\
\hline Vazias (\%) & 70,9 & 19,0 & 77,9 & 54,7 & 79,1 & 72,9 & 74,2 & 90,3 \\
Ocupadas (\%) & 29,1 & 81,0 & 22,1 & 45,3 & 20,9 & 27,1 & 25,8 & 9,7 \\
Total (\%) & 100,0 & 100,0 & 100,0 & 100,0 & 100,0 & 100,0 & 100,0 & 100,0 \\
Total (N) & 7.278 & $\mathbf{4 . 1 3 9}$ & 73.938 & $\mathbf{5 1 . 7 9 7}$ & $\mathbf{1 9 4 . 8 1 5}$ & $\mathbf{2 1 3 . 8 8 8}$ & $\mathbf{1 5 2 . 0 0 9}$ & $\mathbf{8 7 8 . 6 4 8}$ \\
\hline
\end{tabular}

Fonte: IBGE (2011a); Inpe (2011); Bueno (2014).

Nota: Uma mesma célula pode conter mais de uma classe de uso e cobertura da terra.

Existe uma correlação positiva e forte entre volume de população e percentual de área urbana nas células em todos os recortes espaciais $(\rho>0,6)$, mas ela é mais elevada fora de APs $(\rho>0,72)$ do que dentro delas. Nas APs a correlação entre população e área urbana é mais elevada em TIs $(\rho>0,68)$ e em US $(\rho>0,66)$ do que nas UCs de Proteção 
Integral ( $\rho>0,61)$, o que era esperado devido às maiores restrições impostas à presença de população nestas UCs. Com relação à presença de vegetação, o coeficiente negativo dentro e fora de AP confirma o que foi verificado antes quando se analisou o conjunto das células ocupadas, ou seja, o volume de população decresce com o aumento do percentual de vegetação.

TABELA 6

Distribuição das células, por classe de uso e cobertura da terra, segundo localização em relação às Áreas Protegidas

Estado do Pará - 2010

\begin{tabular}{lrrrrrrrr}
\hline & \multicolumn{7}{c}{ Classes de uso e cobertura da terra (células) } \\
\cline { 2 - 8 } Localização & Agricultura & $\begin{array}{c}\text { Área } \\
\text { urbana }\end{array}$ & Hidrografia & Mosaico & Outros & Pasto & Regeneração & Vegetação \\
\cline { 2 - 8 } TI (\%) & 0,1 & 1,0 & 7,1 & 2,8 & 16,0 & 2,3 & 2,9 & 24,0 \\
PI (\%) & 0,1 & 0,5 & 2,9 & 0,7 & 4,2 & 0,9 & 1,4 & 10,7 \\
US (\%) & 0,4 & 12,1 & 26,0 & 8,0 & 21,2 & 6,6 & 7,3 & 22,6 \\
Fora de AP & 99,5 & 86,4 & 64,0 & 88,4 & 58,6 & 90,3 & 88,4 & 42,8 \\
(\%) & 100,0 & 100,0 & 100,0 & 100,0 & 100,0 & 100,0 & 100,0 & 100,0 \\
Total (\%) & 7.278 & 4.139 & 73.938 & 51.797 & 194.815 & $\mathbf{2 1 3 . 8 8 8}$ & $\mathbf{1 5 2 . 0 0 9}$ & $\mathbf{8 7 8 . 6 4 8}$ \\
\hline
\end{tabular}

Fonte: IBGE (2011a); Inpe (2011); Bueno (2014).

Nota: Uma mesma célula pode conter mais de uma classe de uso e cobertura da terra.

Na Figura 1, apresenta-se um painel de mapas que se complementam e permitem verificar que: (A) a maior concentração de células ocupadas ocorre no leste, desde a porção nordeste até o sudeste paraense, reduzindo-se em direção ao oeste; (B) a concentração da ocupação coincide com o entorno das sedes municipais e da Região Metropolitana de Belém, mas também ao longo das rodovias que cortam o estado horizontalmente (BR-230) e verticalmente (BR-163); (C) a grande porção do território destinada às Áreas Protegidas está mais concentrada no centro-oeste do estado; e (D) as classes de uso e cobertura da terra com predomínio de vegetação estão, sobretudo, nas Áreas Protegidas, enquanto as áreas urbanas distribuem-se ao longo das principais rodovias e nas margens dos Rios Tapajós e Amazonas. Grandes mosaicos de conservação como as APs da Terra do Meio, entre os Rios Xingu e Iriri, na porção centro-sul do estado, e muitas áreas classificadas como hidrografia, algumas delas dentro de AP, respondem por expressiva porção dos $90 \%$ do território do estado que não contém domicílios ocupados.

De modo geral, a maior concentração da ocupação do leste para o oeste, a baixa densidade de população em APs e a contiguidade de células sem domicílios ocupados ajudam a visualizar padrões e os significados dos valores anteriormente mencionados. 
FIGURA 1

Distribuição dos domicílios (A), sedes municipais e rodovias (B), Áreas Protegidas (C) e principais classes de uso e cobertura da terra (D)

Estado do Pará - 2010
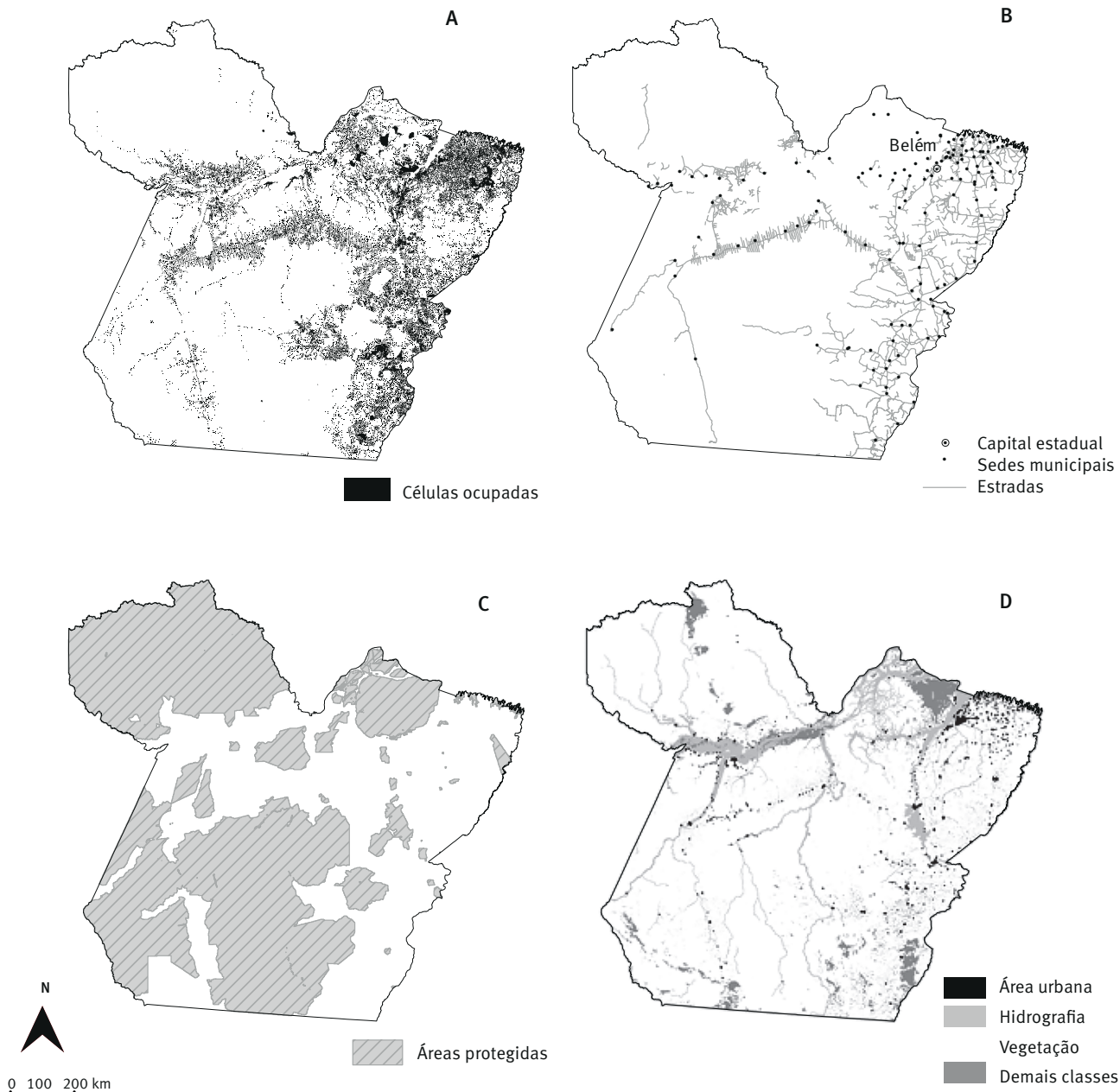

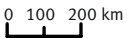

Fonte: IBGE. Censo Demográfico 2010; Brasil (s/d); Inpe (2011); Bueno (2014).

\section{Considerações finais}

A aplicação de uma grade estatística ao caso do Estado do Pará, com o propósito de estudar a distribuição de sua população, potencializa o entendimento da ocupação de Áreas Protegidas (AP) e de como tal ocupação se situa no quadro mais geral. Menos populosas e mais florestadas em comparação ao conjunto do Estado do Pará, as APs apresentam concentração de domicílios ocupados em um número diminuto de células. Os dados permitem identificar nas Áreas Protegidas ocupações urbanas - densidades de domicílios 
relativamente altas (IBGE, 2011a) conjugadas a células classificadas como "área urbana”, pelo TerraClass (INPE, 2011) - que se associam a outros usos e coberturas da terra.

Uma das principais constatações decorrentes da sobreposição de dados de cobertura da terra aos dados de domicílios é a existência de arranjos distintos entre quantidade de domicílios ocupados e tipos de cobertura da terra. Tais arranjos incluem a esperada coincidência de maiores densidades populacionais e a classe "urbana", mas também incluem outras combinações de domicílios ocupados e coberturas associáveis a usos agropecuários e agroflorestais.

As APs caracterizam-se como o lugar das reservas florestais, mas também parecem ter lugar na rede urbana dada a identificada concentração da população em conjuntos de células classificadas como rurais ou urbanas. A expansão das cidades não está necessariamente evitando os espaços protegidos, como se estes fossem barreiras. Os resultados apontam para a necessidade de estudos que aprofundem o entendimento das articulações entre cidade e floresta nas APs, das APs e a rede urbana e dos aglomerados identificados. Cabe realizar estudos de caso que permitam verificar, principalmente em unidades de uso sustentável, como (e se) a criação dessas unidades estimula a redistribuição com concentração da população.

O caso aqui considerado utilizando uma abordagem híbrida de técnicas de agregação e desagregação de dados, de metodologias de álgebra de mapas e sobreposição de planos de informação, bem como cálculo dos coeficientes de Gini e de Pearson, enseja o desenvolvimento de outras análises pertinentes ao campo de população e ambiente, incluindo as demográficas e estatísticas espaciais, as de ecologia da paisagem (como o cálculo de fragmentação florestal) e as baseadas em trabalhos de campo que permitam perceber localmente as dinâmicas que afetam a mobilidade e a redistribuição daqueles indivíduos nas (ou junto das) Áreas Protegidas da Amazônia.

\section{Referências}

BARBIERI, A. F. Mobilidade populacional, meio ambiente e uso da terra em áreas de fronteira: uma abordagem multiescalar. Revista Brasileira de Estudos de População, v. 24, n. 2, p. 225-246, 2007.

BARRETTO FILHO, H. Populações tradicionais: introdução à crítica da ecologia política de uma noção. In: ADAMS, C.; MURRIETA, R.; NEVES, W. A. Sociedades caboclas amazônicas: modernidade e invisibilidade. São Paulo: Annablume, 2006. p. 109-143.

BECKER, B. K. A urbe amazônida: a floresta e a cidade. Rio de Janeiro: Garamond, 2013.

. Fronteira e urbanização repensadas. Revista Brasileira de Geografia, v. 51 n. 3/4, p. 357-371, 1985.

. Undoing myths: the Amazon - an urbanized forest. In: CLUSENER, G. M.; SACHS, I. Brazilian perspectives on sustainable development of the Amazon region. Paris: Unesco e Parthenon Publish Group Limited, 1995. p. 53-89 (Man and Biosphere Series).

BRASIL. Constituição da República Federativa do Brasil. Texto promulgado em 05 de outubro de 1988. Brasília, 1988. 
Decreto n. 4.340, de 22 de agosto de 2002. Regulamenta artigos da Lei n. 9.985, de 18 de julho de 2000, que dispõe sobre o Sistema Nacional de Unidades de Conservação da Natureza - SNUC, e dá outras providências. Brasília, 2002.

Lei n. 9.985, de 18 de julho de 2000. Institui o Sistema Nacional de Unidades de Conservação da Natureza do Brasil (SNUC). Brasília, 2000.

Ministério do Meio Ambiente, dos Recursos Hídricos e da Amazônia Legal. Banco de Dados Geográficos - i3geo. Brasília, s/d. Diponível em: 〈http://mapas.mma.gov.br/i3geo/ datadownload.htm>. Acesso em: 10 jan. 2012.

BRINEGAR, S. J.; POPICK, S. J. A comparative analysis of small area population estimation methods. Cartography and Geographic Information Science, v. 37, n. 4, p. 273-84, 2010.

BUENO, M. C. Grade estatística: uma abordagem para ampliar o potencial analítico de dados censitários. Tese (Doutorado em Demografia) - Universidade Estadual de Campinas - Unicamp, Campinas, 2014.

CARNEIRO DA CUNHA, M.; ALMEIDA, M. Populações tradicionais e conservação ambiental. In: CARNEIRO DA CUNHA, M. Cultura com aspas. São Paulo: Cosac Naify, 2009. p. 277-300.

CARVALHO, M. S.; CÂMARA, G.; CRUZ, O. G.; CORREA, V. Análise espacial de áreas. In: DRUCK, S.; CARVALHO, M. S.; CAMARA, G.; MONTEIRO, A. M. V. (Ed.). Análise espacial de dados geográficos. Brasília: Embrapa, 2004.

CASTRO, M. C. Spatial demography: an opportunity to improve policy making at diverse decision levels. Population Research and Policy Review, v. 26, n. 5, p. 477-509, 2007.

CHAMPION, T.; HUGO, G. New forms of urbanization: beyond the urban-rural dichotomy. Aldershot: Ashgate Publishing, 2003.

CÔRTES, J. C.; D’ANTONA, A. O. Dinâmicas no uso e cobertura da terra: perspectivas e desafios da Demografia. Revista Brasileira de Estudos de População, v. 31, n. 1, p. 191-210, jan./jun. 2014.

D’ANTONA, A.; BUENO, M. C.; DAGNINO, R. Estimativa da população em unidades de conservação na Amazônia Legal brasileira: uma aplicação de grades regulares a partir da Contagem 2007. Revista Brasileira de Estudos de População, v. 30, n. 2, p. 401-428, 2013.

DE SHERBININ, A.; BALK, D.; YAGER, K.; JAITEH, M.; POZZI, F.; GIRI C.; WANNEBO, A. A CIESIN thematic guide to social science applications of remote sensing. Nova York: Center for International Earth Science Information Network (CIESIN), 2002.

DIEGUES, A. As populações tradicionais: conflitos e ambigüidades. In: DIEGUES, A. 0 mito moderno da natureza intocada. 5. ed. São Paulo: NUPAUB-USP, 2004.

EICHER, C. L.; BREWER, C. A. Dasymetric mapping and areal interpolation: implementation and evaluation. Cartography and Geographic Information Science, v. 28, n. 2, p. 125-138, 2001.

GARDNER, T. A. et al. A social and ecological assessment of tropical land uses at multiple scales: the Sustainable Amazon Network. Philosophical Transactions of the Royal Society B-Biological Sciences, v. 368, n. 1619, Jun. 5, 2013.

GOODCHILD, M. F. Research initiative 1: accuracy of spatial databases. Final report. Santa Barbara: National Center for Geographic Information and Analysis, University of California, 1992.

GOTWAY, C. A.; YOUNG, L. J. Combining Incompatible Spatial Data. Journal of the American Statistical Association, v. 97, n. 458, p. 632-648, 2002.

GRASLAND, C.; MADELIN, M. The modifiable areas unit problem. Final report. ESPON - European Spatial Planning Observation Network, 2006. 
GUEDES, G. R.; COSTA, S.; BRONDÍzIO, E. Revisiting the hierarchy of urban areas in the Brazilian Amazon: a multilevel approach. Population and Environment, v. 30, n. 4/5, p. 159-192, 2009.

GUIMARÃES, R. R.; RIOS-NETO, E. G. Comparação entre metodologias de idade-período-coorte para o estudo de uma medida da progressão escolar no Brasil. Revista Brasileira de Estudos de População, v. 28, n. 2, p. 349-367, 2011.

GUZMÁN, J. M.; SCHENSUL, D.; ZHANG, S. Understanding vulnerability and adaptation using census data. In: MARTINE, G.; SCHENSUL, D. (Ed.). The demography of adaptation to climate change. New York, London and Mexico City: UNFPA, IIED e El Colegio de México, 2013.

HOGAN, D. J. População e meio ambiente: a emergência de um novo campo de estudos. In: HOGAN, D. J. (Org.). Dinâmica populacional e mudança ambiental: cenários para o desenvolvimento brasileiro. Campinas: Unicamp, 2007.

HOLT, J. B.; LO, C. P.; HODLER, T. W. Dasymetric estimation of population density and areal interpolation of census data. Cartography and Geographic Information Science, v. 31, n. 2, p. 103-121, 2004.

IBGE - Instituto Brasileiro de Geografia e Estatística. Censo 2010 - Sinopse do Censo Demográfico 2010. Rio de Janeiro, 2011a.

Base de informações do Censo Demográfico 2010: resultados do universo agregados por setor censitário. Rio de Janeiro, 2011b.

Censo 2010: malhas digitais dos setores censitários. Rio de Janeiro, 2011c.

Censo Demográfico 2010 - Características gerais dos indígenas: resultados do universo. Rio de Janeiro, 2012.

INPE - Instituto Nacional de Pesquisas Espaciais. TerraClass 2010: levantamento de informações sobre usos e cobertura da terra na Amazônia. Belém, Inpe/CRA/CPATU, 2011. Disponível em: 〈http://www.inpe.br/cra/projetos_pesquisas/terraclass2010.php〉. Acesso em: 28 jul. 2015.

LANGFORD, M.; UNWIN, D. J. Generating and mapping population density surfaces within a geographical information system. The Cartographic Journal, v. 31, n. 1, p. 21-26, 1994.

LUTZ, W.; PRSKAWETZ, A.; SANDERSON, W. C. Population and environment: methods of analysis. Population and Development Review, v. 28, suppl., 2002.

MARTINE, G. O lugar do espaço na equação população/meio ambiente. Revista Brasileira de Estudos de População, v. 24, n. 2, p. 181-190, 2007.

MEDEIROS, R. Evolução das tipologias e categorias de áreas protegidas no Brasil. Ambiente e Sociedade, v. 9, n. 1, junho 2006.

MONTEIRO, A.; CARDOSO, A. Project URBISAmazônia: what is the nature of the urban phenomenon in the contemporary Amazônia? Cities, places, and networks in the multi-scale configuration of the urban setting in contemporary Amazônia. GLP News, n. 8, p. 26-28, March 2012.

MONTE-MÓR, R. 0 que é o urbano, no mundo contemporâneo. Belo Horizonte: UFMG/Cedeplar, 2006 (Texto para discussão, n. 281).

MOUW, T. Visions of the future: new directions in population research. In: POPULATION ASSOCIATION OF AMERICA ANNUAL MEETING, Los Angeles, USA, 2000.

MROZINSKI JR., R. D.; CROMLEY, R. G. Singly-and doubly-constrained methods of areal interpolation for vector-based GIS. Transactions in GIS, v. 3, n. 3, p. 285-301, 1999.

NICHD - National Institute of Child Health and Human Development. Goals and opportunities: 2002-2006. Bethesda, MD, 2002. 
OIT - Organización Internacioal del Trabajo. Convenio sobre pueblos indígenas y tribales. Organización Internacioal del Trabajo, 1989 (Convenção 169 da OIT aprovada em 27 de junho de 1989, com entrada em vigor em 5 de setembro de 1991). Disponível em: 〈http://www.ilo.org/ ilolex/cgi-lex/convds.pl?C169).

OPENSHAW, S. The modifiable areal unit problem. Concepts and Techniques in Modern Geography, n. 38. Norwich: Geo Books, 1984.

OPENSHAW, S.; RAO, L. Algorithms for reengineering 1991 census geography. Environment and Planning A, v. 27, n. 3, p. 425-446, 1995.

PEREIRA, P.; SCARDUA, F. Espaços territoriais especialmente protegidos: conceito e implicações jurídicas. Ambiente e Sociedade, v. 11, n. 1, jun. 2008.

PLUMEJEAUD, C.; PRUD’HOMME, J.; DAVOINE, P.; GENSEL, J. Transferring indicators into different partitions of geographic space. In: TANIAR, D.; GERVASI, O.; MURGANTE, B.; PARDEDE, E.; APDUHAN, B. (Ed.). Proceedings International Conference on Computational Science and its Applications - ICCA'10. Berlin, Heidelberg: Springer-Verlag, 2010. v. 1, part 1.

RAMOS, F. Três ensaios sobre a estrutura espacial urbana em cidades do Brasil contemporâneo: economia urbana e geoinformação na construção de novos olhares. Tese (Doutorado em Administração Pública e Governo) - Escola de Administração de Empresas de São Paulo, Fundação Getúlio Vargas, São Paulo, 2014.

RASE, D. Dealing with the modifiable areal unit problem: spatial transformation methods for the analysis of geographic data. In: EUROPEAN ENVIRONMENT AGENCY. Towards agri-environmental indicators: integrating statistical and administrative data with land cover information. Copenhagen: EEA, 2001. p. 25-38.

REIBEL, M.; AGRAWAL, A. Areal interpolation of population counts using pre-classified land cover data. Population Research and Policy Review, v. 26, n. 5, p. 619-633, 2007.

REIBEL, M.; BUFALINO, M. E. Street-weighted interpolation techniques for demographic count estimation in incompatible zone systems. Environment and Planning A, v. 37, n. 1, p. 127-139, 2005.

ROLLA, A.; RICARDO, F. Mapas das sobreposições. In: RICARDO, F. (Org.). Terras Indígenas \& Unidades de Conservação da natureza: o desafio das sobreposições. São Paulo: Instituto Socioambiental, 2004. p. 591-619.

SATHLER, D.; MONTE-MÓR, R. L.; CARVALHO, J. A. M. As redes para além dos rios: urbanização e desequilíbrios na Amazônia brasileira. Nova Economia, v. 19, n. 1, p. 11-39, 2009.

SCHUURMAN, N.; LESZCZYBSKI, A.; FIEDLER, R.; GRUND, D.; BELL, N. Building an integrated cadastral fabric for higher resolution socioeconomic spatial data analysis. In: RIEDL, A.; KAINZ, W.; ELMES, G. A. (Ed.). Progress in spatial data handling: $12^{\text {th }}$ International Symposium on Spatial Data Handling. Berlin, Heidelberg, New York: Springer, 2006.

SILVA, J. G. O novo rural brasileiro. Nova Economia, v. 7, n. 1, maio 1997.

TATEM, A. J.; NOOR, A. M.; VON HAGEN, C.; DI GREGORIO, A.; HAY, S. I. High resolution population maps for low income nations: combining land cover and census in east Africa. PLoS ONE, v. 2, n. 12, e1298, 2007.

TOBLER, W.; DEICHMANN, U.; GOTTSEGEN, J.; MALOY, K. World population in a grid of spherical quadrilaterals. International Journal of Population Geography, v. 3, p. 203-225, 1997.

VOSS, P. R. Demography as a spatial social science. Population Research and Policy Review, v. 26, n. 5/6, p. 457-476, 2007. 
WEEKS, J. R. The role of spatial analysis in demographic research. In: GOODCHILD, M. F.; JANELLE, D. G. (Ed.). Spatially integrated social science. New York: Oxford University Press, 2004.

WRIGLEY, N. Revisiting the modifiable areal unit problem and the ecological fallacy. In: CLIFF, A.; GOULD, P.; HOARE, A.; THRIFT, N. (Ed.). Diffusing geography: essays for Peter Haggett. New York: Wiley-Blackwell, 1995.

$\mathrm{XIE}, \mathrm{Y}$. The overlaid network algorithms for areal interpolation problem. Computers, Environment and Urban Systems, v. 19, n. 4, p. 287-306, 1995.

ZHU, Y. Changing urbanization processes and in situ rural-urban transformation: reflections on China's settlement definitions. In: CHAMPION, A. J.; HUGO, G. J. (Ed.). New forms of urbanization: beyond the urban-rural dichotomy. Aldershot: Ashgate, 2004. p. 207-228.

ZHU, Y.; QI, X.; SHAO, H.; HE, K. The evolution of China's in situ urbanization and its planning and environmental implications: case studies from Quanzhou municipality. In: DE SHERBININ, A.; RAHMAN, A.; BARBIERI, A.; FOTSO, J.; ZHU, Y. (Ed.). Urban population-environment dynamics in the developing world: case studies and lessons learned. Paris: Committee for International Cooperation in National Research in Demography, 2009.

\title{
Sobre os autores
}

Álvaro de Oliveira D’Antona é doutor em Ciências Sociais. Professor na Faculdade de Ciências Aplicadas da Universidade Estadual de Campinas (FCA/Unicamp).

Ricardo de Sampaio Dagnino é doutor em Demografia e pós-doutorando em Análises Demográficas Espaciais na Faculdade de Ciências Aplicadas da Universidade Estadual de Campinas (FCA/Unicamp), com bolsa da Fapesp (2015/16270-2).

Maria do Carmo Dias Bueno é engenheira, doutora em Demografia. Tecnologista em informações geográficas e estatísticas do Instituto Brasileiro de Geografia e Estatística (IBGE).

\section{Endereço para correspondência}

\author{
Álvaro de Oliveira D’Antona \\ Av. José Bonifácio, 1111 apto. 23 \\ 13091-140 - Campinas-SP, Brasil \\ Ricardo de Sampaio Dagnino \\ Rua Ângelo Grigol, 88 \\ 13085-460 - Campinas-SP, Brasil \\ Maria do Carmo Dias Bueno \\ Rua Uberaba, 86 apto. 203, Grajaú \\ 20561-240 - Rio de Janeiro-RJ, Brasil
}

\section{Abstract}

Population distribution and land cover: the protected areas in Pará, Brazil in 2010

The objective of this study is to analyze population distribution in the state of Pará in Brazil using data from the2010 Population Census in association with the land use and land cover data from TerraClass arranged in a statistical grid. The role of 113 Protected Areas (including 46 Indigenous Lands, 51 Sustainable Use Conservation Units and 16 Integral Protection Conservation Units) is 
analyzed from the standpoint of their demographic rural-urban gradients and in terms of their land use cover. Information on the use and cover of land in Protected Areas along with census data were incorporated into a statistical grid using GIS. The spatial relationship of information layers in the cells indicates that the state's population is highly concentrated in a few areas, a pattern that is reproduced to some extent in the Protected Areas (Gini coefficient for the distribution of households is higher than 0.9). The area of the Protected areas is less populated and retains a greater extension of forested areas, by comparison to the state. Despite having extensive segments devoid of occupied households and the largest expanse of forest coverage (57\%) in the state, Protected Areas also have urban areas associated with other uses and land cover change. The results indicate that population dynamics and changes in the uses and covering of land are related in a broader manner, thereby suggesting the need for reflection on urbanization and changes in land use and land cover change within a more integrated approach.

Keywords: Pará. Protected areas. Spatial distribution. Statistical grid. Land use and land cover.

\section{Resumen}

Distribución de la población y cobertura de la tierra: el lugar de las Áreas Protegidas en Pará, Brasil en 2010

El objetivo de este trabajo es analizar la distribución de la población del estado de Pará en Brasil a partir de información del Censo Demográfico de 2010 asociada a datos de uso y cobertura de la tierra provenientes de TerraClass, dispuestos en una cuadrícula estadística. Se examina el papel que desempeñan 113 Áreas Protegidas, 46 Tierras Indígenas, 51 Unidades de Conservación de Uso Sustentable y 16 Unidades de Conservación de Protección Integral en el gradiente ruralurbano desde el punto de vista de la población y en relación con los usos y la cobertura de la tierra existentes en ellas. La información relativa a las Áreas Protegidas, al uso y la cobertura de la tierra y los datos censales fueron incorporados a la cuadrícula estadística usando un Sistema de Información Geográfica. La relación espacial entre los estratos de información en la cuadrícula indica que la población del estado está bastante concentrada, una tendencia que se reproduce en las Áreas Protegidas (el coeficiente de Gini de la distribución de las viviendas es superior a $0,9)$. Las Áreas Protegidas se configuran como zonas menos pobladas y con más forestación que el resto del estado. A pesar de la presencia de extensas áreas sin viviendas ocupadas y de la mayor extensión de los bosques de Pará (57\%), se identifican en estas áreas usos urbanos asociados a otros usos y coberturas de la tierra. Los resultados indican que las dinámicas de la población y los cambios en los usos y la cobertura de la tierra están relacionados de manera más amplia, estimulando por lo tanto una reflexión más integrada sobre la vinculación entre la urbanización y estos cambios.

Palabras clave: Pará. Áreas Protegidas. Distribución espacial. Cuadrícula estadística. Uso y cobertura de la tierra.

Recebido para publicação em 31/07/2015 Recomendado para publicação em 16/09/2015

Aceito para publicação em 30/10/2015 
